\title{
Surgical removal of a fractured balloon catheter from deep femoral artery: a case report
}

\author{
Erdal Şimşek, Eren Günertem, İbrahim Erkengel, Serkan Mola, Gökhan Lafçı, Kerim Çağlı
}

Received: February 19, 2016 Accepted: June 01, 2016 Published online: July 21, 2016

\begin{abstract}
An intravascular fracture of balloon catheters during peripheral catheterization is uncommon. This is a rare, but a serious complication of interventional procedures, which may lead to bleeding or lower limb ischemia and require an emergency surgical intervention. Herein, we present a 71-year-old male case in whom a balloon catheter was broken inside of the deep femoral artery and retrieved surgically. A broken and entrapped catheter is one of the extraordinary complications in this type of applications. Fortunately, it is seen rarely and treated either interventional or surgical techniques.
\end{abstract}

Keywords: Deep femoral artery; fractured balloon catheter; pseudoaneurysm.

The percutaneous interventions are commonly used in the treatment of peripheral vascular diseases. There is a number of complications related to these procedures. A fractured segment of angioplasty balloon catheter in a peripheral artery is one of them. Herein, we report a case in whom a balloon catheter was broken inside of the deep femoral artery and retrieved surgically.

\section{CASE REPORT}

A 71-year-old man was admitted our hospital with a pain on the right inguinal area for a month after a coronary intervention via the right femoral artery. Doppler ultrasound confirmed a pseudoaneurysm originating from the deep femoral artery, which was measured $100 \times 70 \times 50 \mathrm{~mm}$ in size. An endovascular treatment was planned. The interventionists placed a covered stent across the hole in the arterial wall to prevent blood flow from the deep femoral artery to the pseudoaneurysm sac. However, it broke down from the neck during retrieval of the balloon catheter. The interventionists tried several attempts to snare it out; however, all attempts failed. The patient was referred to us for surgery. A written informed consent was obtained from the patient. Following the skin incision, a large hematoma was seen and, then, drained. The common femoral artery and distal portion of the deep femoral artery were freed with careful dissection and nylon tapes were placed around the vessel (Figure 1). The broken end of the balloon catheter was seen into the deep femoral artery and removed (Figure 2). The artery was, then, repaired with 6-0 prolene sutures. The procedure was performed under local anesthesia. After surgery, the patient was followed for three days in the ward and, then, he was discharged.

\section{DISCUSSION}

The percutaneous interventions are routinely being used worldwide for the management of peripheral vascular diseases such as stenosis, arteriovenous fistulas or pseudoaneurysm. However, there is a number of complications which may arise during this process. A fractured segment of angioplasty balloon catheter in a peripheral artery poses the risk of undesired complications, such as bleeding or acute embolism, leading to lower limb ischemia. ${ }^{[1]}$

Non-surgical retrieval of broken catheters has been reported and most of them were totally localized in the intravascular space. ${ }^{[2,3]}$ Earlier, ultrasound was used to show the location and size of any radiolucent foreign body and percutaneous retrieval of nonopaque foreign bodies were carried out under the ultrasound guidance. ${ }^{[4]}$ In this case, retrieval of a broken catheter was performed surgically, although interventional methods were tried before surgery.

Department of Cardiovascular Surgery, Türkiye Yüksek İhtisas Training and Research Hospital, Ankara, Turkey

Corresponding author: Eren Günertem, MD. Türkiye Yüksek İhtisas Eğitim ve Araştırma Hastanesi Kalp ve Damar Cerrahisi Kliniği, 06230 Altındağ, Ankara, Turkey.

Tel: +90 555-60057 70 e-mail: egunertem@yahoo.com.tr 


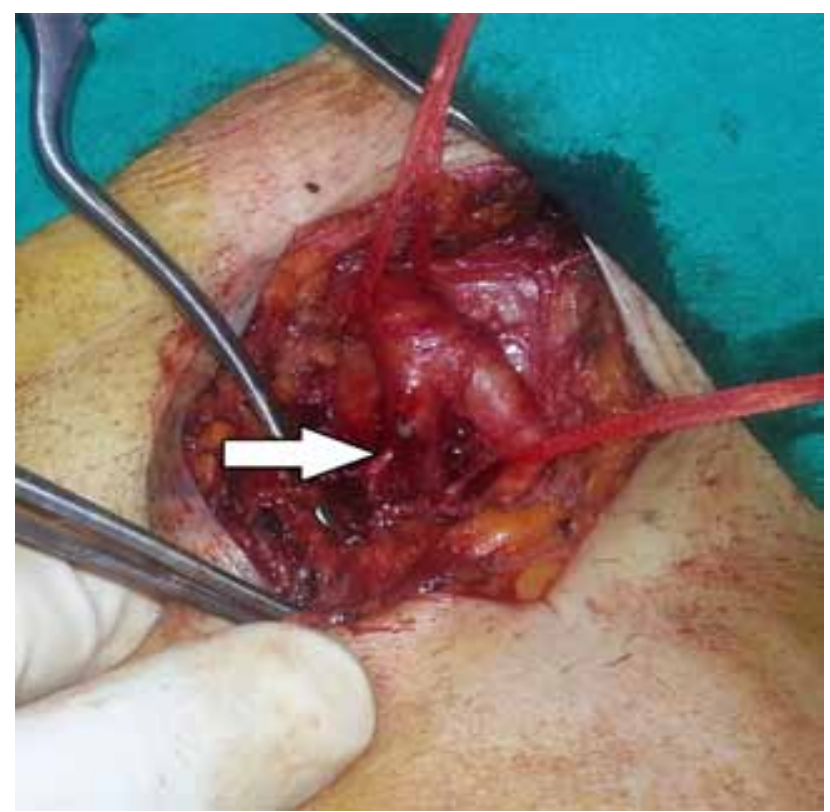

Figure 1. An intraoperative image. Arrow shows a broken balloon catheter into the deep femoral artery.

Furthermore, the selection of an optimal catheter material and appropriate size is critical. Improper entry point on the vessel can cause serious complications. In our case, the interventionists put the sheath on the deep femoral artery. Choosing the common femoral artery for access could have reduced angulation on the neck of the catheter and prevented breakage. If catheter size is incompatible with the sheath size, the interventionist can face similar challenges. Therefore, using a longer sheath and choosing the common femoral artery for entry point would have been precluded this complication in our case. In recent years, interventional techniques have become widely adopted thanks to their easy-touse nature without pain and not requiring general anesthesia.

In conclusion, although intravascular fractures of angiography catheters during peripheral catheterizations are rare complications, retrieval of a broken and entrapped catheter fragments may be

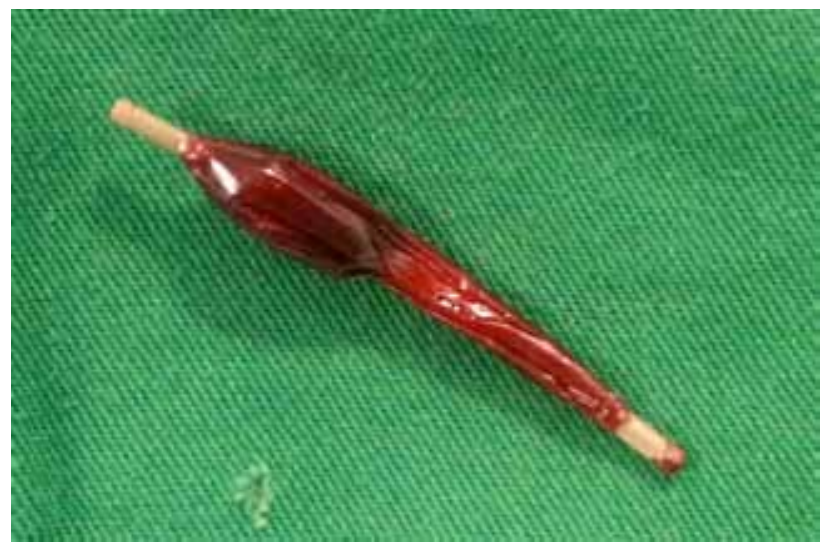

Figure 2. The broken balloon catheter.

possible with either interventional or surgical methods. Therefore, physicians should be aware of such problems and inform patients. We believe that this report will guide to physicians on how to manage this type of complication surgically.

\section{Declaration of conflicting interests}

The authors declared no conflicts of interest with respect to the authorship and/or publication of this article.

\section{Funding}

The authors received no financial support for the research and/or authorship of this article.

\section{REFERENCES}

1. Krajcer Z, Howell MH. Update on endovascular treatment of peripheral vascular disease: new tools, techniques, and indications. Tex Heart Inst J 2000;27:369-85.

2. Woodhouse JB, Uberoi R. Techniques for intravascular foreign body retrieval. Cardiovasc Intervent Radiol 2013;36:888-97.

3. Carroll MI, Ahanchi SS, Kim JH, Panneton JM. Endovascular foreign body retrieval. J Vasc Surg 2013;57:459-63.

4. Woo VL, Gerber AM, Scheible W, Seo KW, Bookstein JJ, Leopold GR. Real-time ultrasound guidance for percutaneous transluminal retrieval of nonopaque intravascular catheter fragment. AJR Am J Roentgenol 1979;133:760-1. 